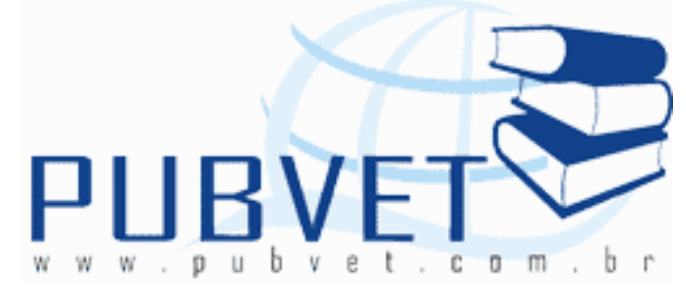

PUBVET, Publicações em Medicina Veterinária e Zootecnia.

\title{
Carcinoma de células escamosas em região ocular e periocular de gato doméstico
}

David Baruc Cruvinel Lima ${ }^{1}$, Islla Raquel Medeiros da Silva ${ }^{1}$, Karoline Gonçalves Moraes $^{2}$, Fabiana Cristina Belchior ${ }^{3}$, Marcelo Campos Rodrigues ${ }^{4}$

${ }^{1}$ Acadêmico de Medicina Veterinária - Centro de Ciências Agrárias (CCA) Universidade Federal do Piauí (UFPI).

${ }^{2}$ Médica Veterinária - Residente em Clínica Médica e Cirúrgica de pequenos animais do Hospital Veterinário Universitário - Centro de Ciências Agrárias (CCA) - Universidade Federal do Piauí (UFPI).

${ }^{3}$ Médica Veterinária.

${ }^{4}$ Médico Veterinário, Doutor em Medicina Veterinária - Centro de Ciências Agrárias (CCA) - Universidade Federal do Piauí (UFPI).

\section{Resumo}

O carcinoma de células escamosas é uma neoplasia raramente encontrada no globo ocular de gatos, acometendo principalmente animais idosos e de pelagem clara. O objetivo deste estudo foi relatar o caso de um felino, macho, sem raça definida que apresentava toda a região ocular e periocular direita comprometida, submetido a procedimento cirúrgico de remoção do globo ocular. A confirmação do diagnóstico foi baseada no exame histopatológico. 0 tratamento preconizado foi à excisão cirúrgica do tumor. Conclui-se que apesar desta neoplasia ser de ocorrência comum na espécie felina, o envolvimento da 
região ocular e periocular não é habitual, sendo essencial um diagnóstico precoce a fim de se obter um prognóstico satisfatório.

Palavras-chave: Felino; Carcinoma; Cirurgia; Histopatológico

\title{
Squamous cell carcinoma in eyepiece and periocular region of domestic cat
}

\begin{abstract}
The squamous cell carcinoma is a tumor rarely found on ocular globe of cats, affecting mainly elderly animals and clear coat. The objective of this study was to report the case of a cat, male mixed breed that presented all the right eyepiece and periocular region compromised, submitted to surgical removal of the eyeball. The diagnosis was based on histopathologic examination. The treatment advocated was the surgical excision of the tumor. It is concluded that despite this being a commonly occurring cancer in feline species, ocular and periocular involvement is not common, early diagnosis is essential in order to obtain a satisfactory prognosis.
\end{abstract}

Keywords: Feline; Carcinoma; Surgery; Histopathologic

\section{Introdução}

A quantidade de animais domésticos diagnosticados com doenças oncológicas em clínicas e hospitais veterinários tem aumentado nos últimos anos, sendo estas, responsáveis pela morte de grande parte dos pacientes acometidos. As doenças neoplásicas podem se originar em todos os tecidos do organismo e apresentar uma grande variação morfológica (SALVADO, 2010).

O globo ocular não representa uma região comumente acometida em gatos que são diagnosticados com carcinoma de células escamosas, que ocorre normalmente em animais brancos, idosos e nas raças que possuem áreas despigmentadas, principalmente nos planos nasais e auriculares devido ao fato 
desta afeç̧ão estar diretamente relacionada à exposição dos animais a radiação ultravioleta (MELO, 2008).

O diagnóstico é confirmado pelo exame histopatológico, onde baseado nas características citológicas predominante, determina-se o tipo de neoplasia e sua classificação. Nos carcinomas de células escamosas, as células são normalmente individualizadas, com núcleos grandes, nucléolo evidente e sem vacúolos citoplasmáticos (NELSON; COUTO, 2006).

Em gatos, os tipos de lesões comumente encontradas nesta enfermidade são do tipo ulcerativo pré-invasivas que quando não tratadas precocemente evoluem para lesões invasivas, podendo ocasionar metástases em linfonodos regionais e nos pulmões. O paciente possui maiores chances de recuperação quando o tratamento é estabelecido precocemente e o tipo de intervenção terapêutica deve ser estabelecido de acordo com a disposição tumoral, estado geral do paciente e colaboração do proprietário, sendo que a remoção cirúrgica do tumor é o tratamento utilizado com maior frequência. Assim sendo, o prognóstico está diretamente relacionado à precocidade do diagnóstico (FERREIRA et al., 2006; BISTNER, 2007).

Diante do exposto, o objetivo deste trabalho foi relatar o caso de um felino diagnosticado com carcinoma de células escamosas em região ocular e periocular submetido a procedimento cirúrgico de remoção do globo ocular.

\section{Relato de Caso}

Um felino, macho, sem raça definida, pelagem clara e pesando $3,5 \mathrm{Kg}$ foi abandonado no Hospital Veterinário Universitário (HVU) da Universidade Federal do Piauí apresentando ferimento no olho direito. Ao exame clínico, observou-se extensa área ulcerativa abrangendo a região ocular e periocular, com presença de secreção serossanguinolenta e tecido granulomatoso. A lesão apresentava cerca de $5 \mathrm{~cm}$ de diâmetro (figura 1). O tratamento preconizado foi cirúrgico. O protocolo pré-cirúrgico constou de jejum hídrico e alimentar de 12 horas, antibioticoterapia profilática com penicilina benzatina (240.000 
$\mathrm{UI} / \mathrm{kg}$, via intramuscular - IM), tramadol $(4 \mathrm{mg} / \mathrm{kg}, \mathrm{IM})$, meloxicam $(0,2 \mathrm{mg} / \mathrm{kg}$, via subcutânea - SC). Como medicação pré-anestésica (MPA) foi utilizado acepromazina a $0,2 \%(0,1 \mathrm{mg} / \mathrm{kg}, \mathrm{IM})$. Seguidos 15 minutos da MPA, a indução foi realizada com proporfol $(4 \mathrm{mg} / \mathrm{kg}$, via intravenosa) e a manutenção anestésica foi instituída com isofluorano em circuito semiaberto. A técnica cirúrgica utilizada foi a de exanteração do globo ocular (figura 2). Após o procedimento cirúrgico foram coletados fragmentos da massa tumoral, que foram encaminhados para realização de exame histopatológico (figura 3). Um dreno foi colocado no local da ferida a fim de drenar secreções pós-cirúrgicas e as bordas cirúrgicas aproximadas e suturadas em padrão separado captonado com fio de náilon 3-0 (figura 4). Foi prescrito no pós-operatório antiinflamatório Meloxican $0,2 \%(0,2 \mathrm{mg} / \mathrm{kg}, \mathrm{SC})$ a cada 24 horas durante 5 dias, antibioticoterapia a base de cefalotina $(30 \mathrm{mg} / \mathrm{kg}$, IM) a cada 12 horas durante 5 dias e limpeza da ferida cirúrgica com solução fisiológica e digluconato de Clorexidina. O exame histopatológico confirmou o diagnóstico de carcinoma de células escamosas.

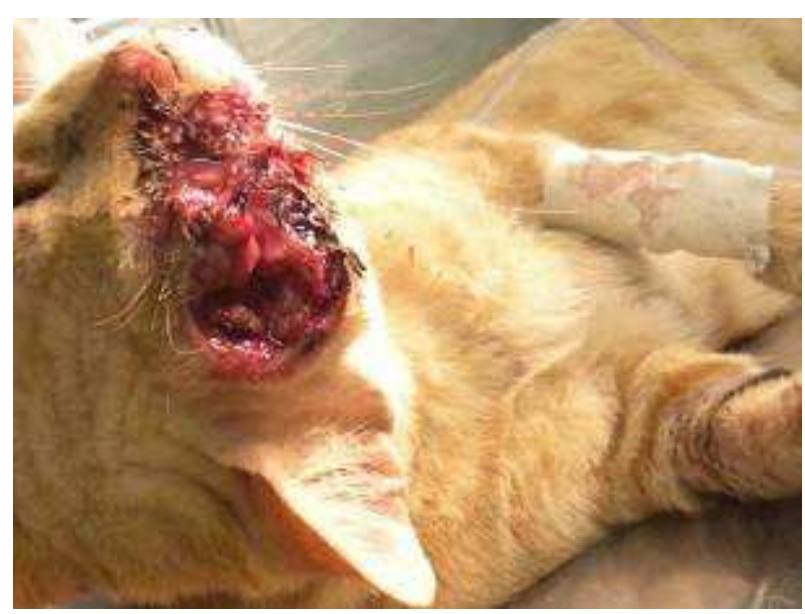

Figura 1. Carcinoma de células escamosas em região ocular e periocular direita em felino doméstico 
LIMA, D.B.C. et al. Carcinoma de células escamosas em região ocular e periocular de gato doméstico. PUBVET, Londrina, V. 7, N. 19, Ed. 242, Art. 1597, Outubro, 2013.

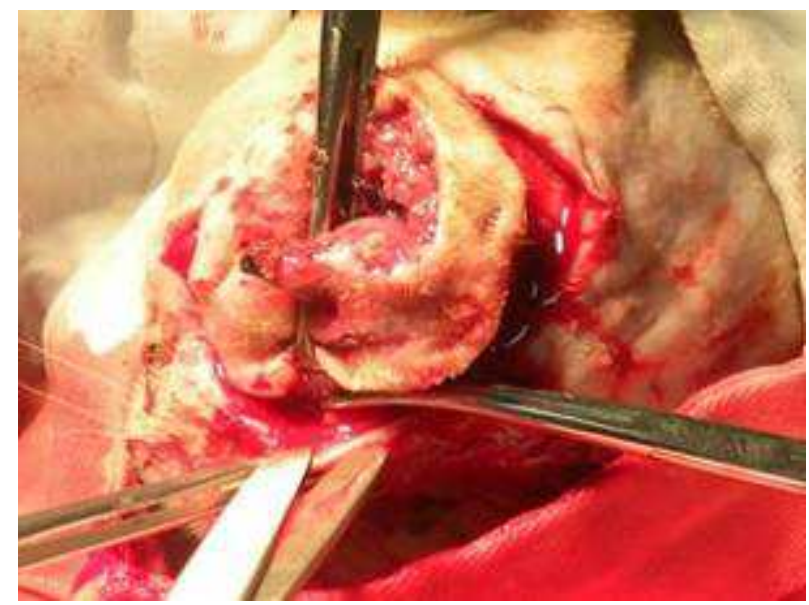

Figura 2. Remoção cirúrgica de globo ocular direito de felino doméstico diagnosticado com carcinoma de células escamosas.

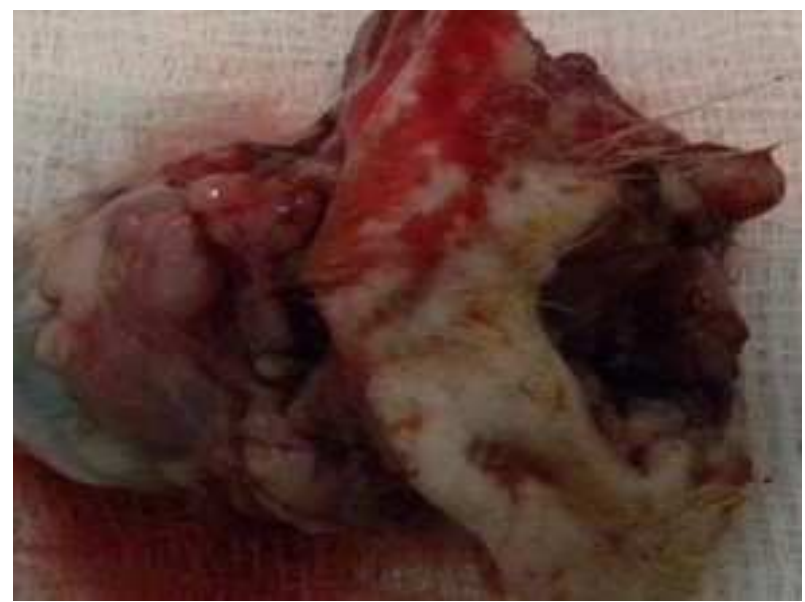

Figura 3. Massa tumoral presente em região ocular e periocular de felino doméstico diagnosticado com carcinoma de células escamosas.

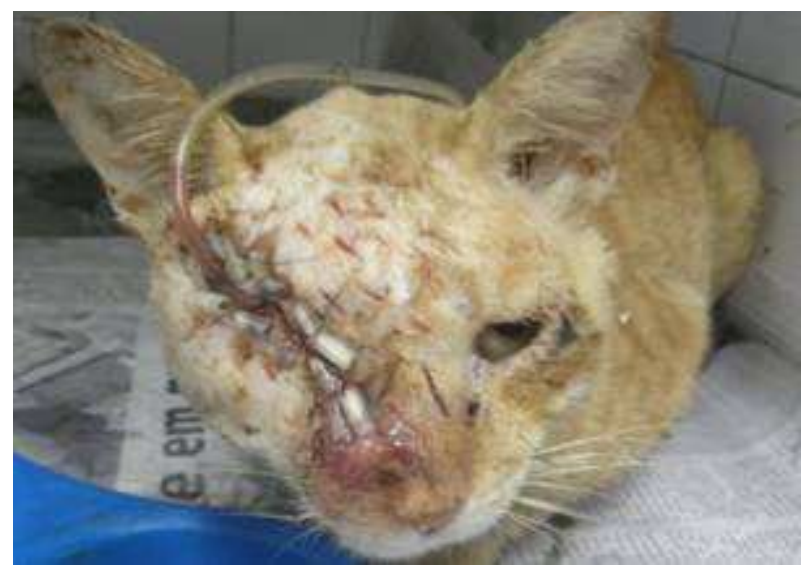

Figura 4. Felino doméstico em recuperação após remoção cirúrgica do globo ocular direito. 


\section{Discussão}

O carcinoma de células escamosas é uma neoplasia maligna onde as células se multiplicam de modo desordenado, infiltrando-se nos tecidos vizinhos, destruindo-os podendo promover focos de metástase. Possui sua origem no epitélio escamoso estratificado e as células lesadas são cerátinocitos, sendo induzido pela exposição do paciente a luz ultravioleta (SANTOS et al., 2004). No presente caso, o felino apresentava toda a região ocular direita comprometida pela presença da massa tumoral, apresentando lesões típicas dessa enfermidade.

Clinicamente, os pacientes acometidos apresentam lesões hiperêmicas, crostosas que evoluem para úlceras e invasão dos tecidos adjacentes. O envolvimento de toda a região ocular não é comum e geralmente as lesões estão localizadas no plano nasal (MAFFEZZOLLI \& ZOTTI, 2007). No caso relatado, o gato apresentava o quadro clínico característico deste tipo de neoplasia, entretanto, as lesões limitavam-se a região ocular e periocular.

Redaelli et al. (2007) afirmam que o exame histopatológico é a principal ferramenta para confirmação do diagnóstico dessa doença oncológica, por possuir uma boa especificidade e o tratamento preconizado é a retirada cirúrgica do tumor com uma elevada margem de segurança. No caso descrito, a confirmação do diagnóstico foi realizada através do exame histopatológico e o tratamento cirúrgico possibilitou a retirada total do tumor.

O diagnóstico precoce exerce influência positiva no prognóstico de pacientes acometidos por doenças neoplásicas, além do fator prevenção, onde os proprietários de gatos susceptíveis a esta neoplasia devem controlar a exposição destes animais a luz solar (MELO, 2008). No relato apresentado não foi possível conhecer o histórico do paciente, visto, este ser abandonado, impossibilitando a determinação exata do tempo da lesão e a afirmação de um prognóstico positivo. 
LIMA, D.B.C. et al. Carcinoma de células escamosas em região ocular e periocular de gato doméstico. PUBVET, Londrina, V. 7, N. 19, Ed. 242, Art. 1597, Outubro, 2013.

\section{Conclusão}

Conclui-se que o carcinoma de células escamosas é um tipo de neoplasia de ocorrência comum na espécie felina, principalmente em animais idosos e de pelagem clara, entretanto, o envolvimento da região ocular e periocular não é habitual.

O sucesso do tratamento está diretamente relacionado ao diagnóstico precoce da enfermidade e a prevenção é principal maneira de se evitar essa neoplasia.

\section{Referências}

BISTNER, S. I. Olho e Órbita. In: SLATTER, D. Manual de cirurgia de pequenos animais. 3 ed. Barueri: Manole, 2007. p. 2426-2427.

FERREIRA, I.; RAHAL, S. C.; FERREIRA, J.; CORRÊA, T. P. Terapêutica no carcinoma de células escamosas cutâneo em gatos. Ciência Rural, v. 36, n. 3, p. 1027-1033, 2006.

MAFFEZZOLLI, A. C.; ZOTTI, E. R. Carcinoma de células escamosas em felinos. 2007. 39 f. Monografia ( Especialização em Clínica Médica dos Felinos Domésticos) - Universidade Castelo Branco.

MELO, G. P. Carcinoma de células escamosas (em felinos) - relato de caso. 2008. 19 f. Monografia (Especialização em Clínica Médica de Pequenos Animais) - Universidade Federal Rural do Semi-árido, UFERSA.

NELSON, R. W.; COUTO, C. G. Manual de medicina interna de pequenos animais. 2 ed. Rio de Janeiro: Elsevier, 2006. P. 824.

REDAELli, R.; ALBUQUERQUE, L.; FAGANELLO, C. S.; RODARTE, A. C.; MARQUES, J. M. V.; OLIVEIRA, L. O.; LEAL, J. S.; DRIEMEIR, D.; PIGATTO, J. A. T. Carcinoma das células escamosas na terceira pálpebra em um cão. Acta Scientiae Veterinarie, v.35, n. supl 2, p. s644 - s645, 2007.

SALVADO, I. S. S. Estudo retrospectivo das neoplasias em canídeos e felídeos domésticos, analisadas pelo laboratório de anatomia patológica da faculdade de medicina veterinária da universidade técnica de lisboa, no período compreendido entre 2000 e 2009. 2010.

97 f. Dissertação (Mestrado Integrado em Medicina Veterinária) - Faculdade de Medicina Veterinária, Universidade Técnica de Lisboa.

SANTOS, P. C. G.; RODER, P. R.; GUIMARÃES, J. G. P. Carcinoma de células escamosas em gatos: relato de caso. Revista Científica Eletrônica de Medicina Veterinária, v. 2, n. 3, 2004. 